\title{
Comparative Study on Various Sympathetic Stimulants in Intestinal Canal System
}

\author{
by \\ Hiroshi FURUSAWA*, Toyoyuki TAMURA*, \\ and Atsushi SAITO*
}

With recent progress in gerontology researches have been very active in the field of so-called autonomic nerve block-drugs which are used for the cure of hypertension. It is widely regarded to be important, at the same time, to notice sympathetic stimulants which have the contrary effect as emergency drugs for cases of bronchial asthma and shocks. Just as there are reported many kinds of autonomic nerve block-drugs, so there are known many sympathetic stimulants such as Adrenalin, Noradrenalin, Phenylephrine, Ephedrine, Methylephedrine, and Isopropylasterenol among others. However, comparative studies hitherto carried among these drugs are by no means perfect in that they are fragmentary in treatment.

In the following paper, the authors attempt at a comprehensive comparison of these sympathetic stimulants as regards their action upon the intestinal canal system.

\section{Experimental Material and Technique}

The following are the chemical structures of various sympathetic stimulants subjected to the present experiment.

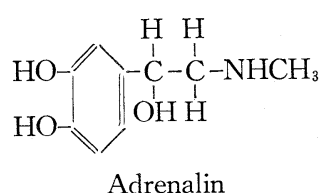

Adrenalin

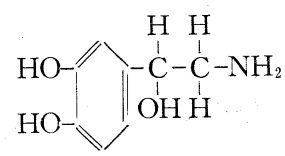

Noradrenalin<smiles>CCNCC1CCC2OC1CCC2O</smiles>

Phenylephrine<smiles>CC(O)[NH+](C)C</smiles>

Ephedrine<smiles>CC(Cl)NCC(O)c1ccc(O)cc1</smiles>

Isopropylasterenol hydrcchloride

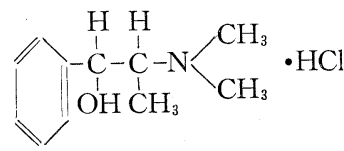

Methylephedrine<smiles>CCC(C)(C)NCC(O)c1ccc(O)cc1O</smiles>

Isopropylasterenol sulphate

* 古沢 博, 田村豊幸, 齊藤 篤: Dept. of Pharmacology, Nihon Univ. School of Dentistry (Director: Prof. Bunjiro TERADA) 
The drugs used were those available on the commercial market, which included $0.1 \%$ solutions of Adrenalin and noradrenalin (made by Sankyo Pharmaceutical Co., Tokyo) respectively, $1 \mathrm{mg} / \mathrm{ml}$ of Neocynezine (made by Kowa Chemical Co., Tokyo), $4 \%$ solution of Ephedrine (Dainihon Pharmaceutical Co., Tokyo), $40 \mathrm{mg} / \mathrm{ml}$ of methylephedrine (TANABE Pharmaceutical Co., Tokyo), Isopropylasterenol hydrochloride and isopropylasterenol sulphate (both made by Kaken-Kagaku Co., Tokyo).

By way of experimental material, the jejunums of domestic rabbits were used and they were placed in Jyrode solution of $40 \mathrm{~mol}$ based on MAGNUS method. Changes which took place subsequently have been recorded by means of the kymograph.

\section{Experimental Results}

It is a known fact that when the terminal of sympathetic nerves running through intestinal canals is excited, it tends to relax itself and when the degree is advanced the autonomic movement comes to a stop while in the position of relaxation.

Using the above fact as an indicator, the authors first tried to obtain relaxation on the test jejunums and subsequently attempted to measure the quantity of each drug which would cause the stoppage of autonomic nerves through excitation on the part of their

Fig. 1
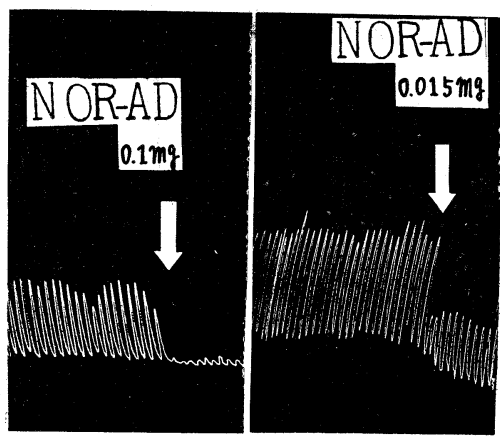

Case of Noradrenalin
Fig. 3

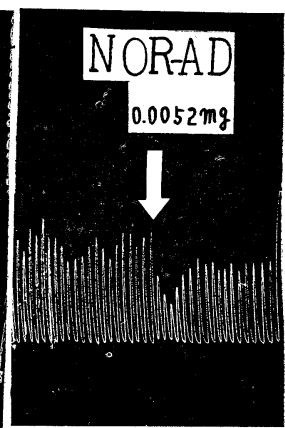

Fig. 6

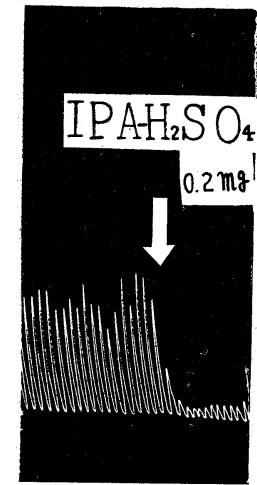

Fig. 5

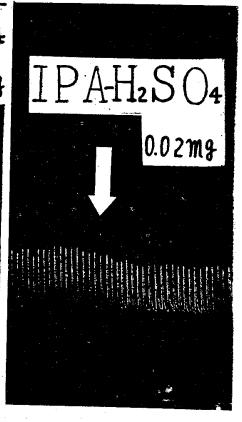

Case of Isopropylasterenol sulphate 
terminal. Lastly, efforts were made to obtain the concentration of each drug which would cause the stoppage in the half-way manner, that is, the one half of the quantity on the way to the complete stoppage.

Figures 1,2 and 3 show the result as regards Noradrenalin, Figs. 4, 5 and 6 the result of Isopropylasterenol sulphate, and Figs. 7, 8 and 9 the result of Isopropylasterenol hydrochloride respectively. They are arranged in the order of strong degrees.

Fig. 7

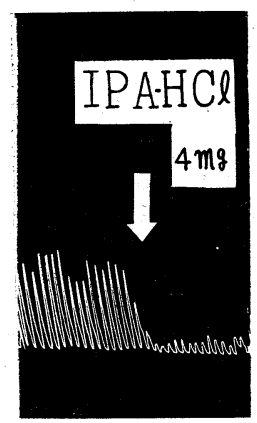

Fig. 9

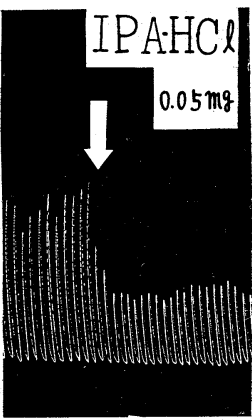

Case of Isopropylasterenol hydrochloride

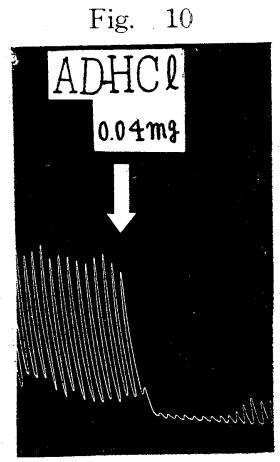

TABLE 1

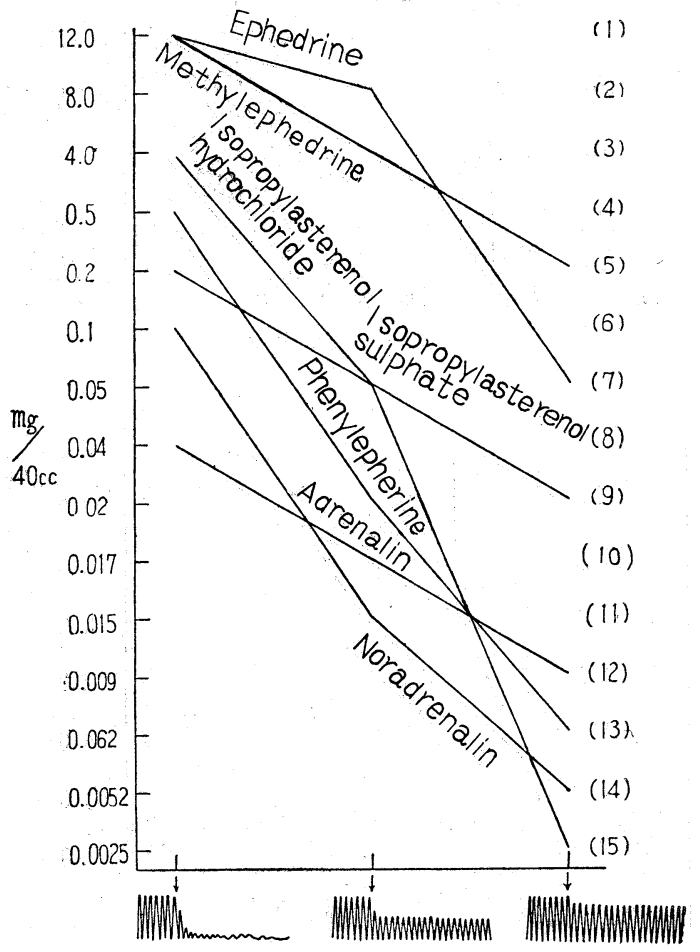


Based on these various results as an indication, similar tests were further conducted on the seven drugs altogether mentioned previously. Table 1 is a graphic presentation of the set of these results obtained.

The ordinate of the Table indicates the required quantity of each drug in terms of $\mathrm{mg} / 40 \mathrm{ml}$ to bring forth the effects shown at the bottom.

As an illustration, the strongest dose of Noradrenalin (Fig. 3) will correspond to that of Adrenalin hydrochloride (Fig 10) in effects.

In an effort to present the fact in clearer fashion the following method is to be adopted. With reference to figures given in brackets in Table 1 , a point on the ordinate corresponding to $12 \mathrm{mg}$ is assumed to be a unit of 1 and 15 is set at a point of 0.0025 . If a certain drug requires $12 \mathrm{mg}$ for its function, it is rated as weak and marked with 1 point. Conversely, when some other drug requires only $0.0025 \mathrm{mg}$ for its function, it is rated as strong and marked with 15 points. Thus, three sets of ratings such as strong, medium and weak have been devised in tabulating the results. Table 2 is a rearrangement of these results in the order of their effects, the larger number indicating the stronger effects.

We are enabled by this Table to know that Adrenalin hydrochloride is the one which possesses the strongest effects; its strong dose, medium dose and weak dose being $0.04 \mathrm{mg}, 0.017 \mathrm{mg}$ and $0.009 \mathrm{mg}$ respectively. In terms of points, we can obtain such a

\section{TABLE 2}

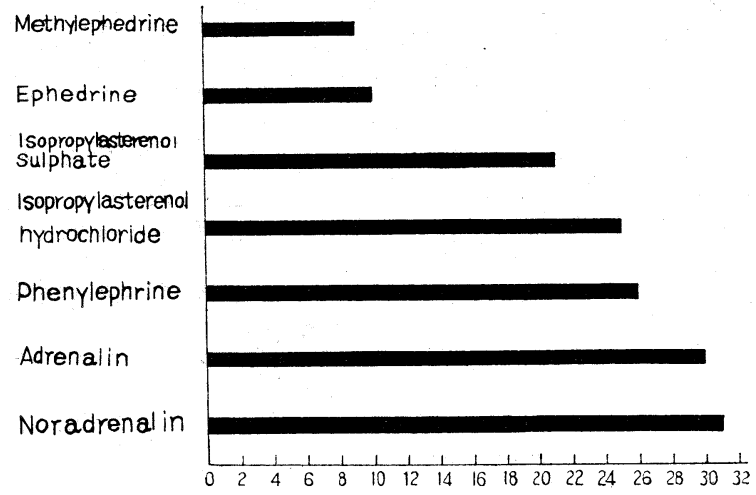

\begin{tabular}{ll|c|c|c}
\hline \multicolumn{1}{c|}{ Drugs } & Strong & Medium & Weak \\
\hline 1. & Noradrenalin & 0.1 & 0.015 & 0.0052 \\
\hline 2. & Adrenalin & 0.04 & 0.017 & 0.009 \\
\hline 3. & Phenylephrine & 0.5 & 0.02 & 0.0062 \\
\hline 4. & Isopropylasterenol hydrochloride & 4.0 & 0.05 & 0.0025 \\
\hline 5. & Isopropylasterenol sulphate & 0.2 & 0.05 & 0.02 \\
\hline 6. & Ephedrine & 12.0 & 0.8 & 0.05 \\
\hline 7. & Methylephedrine & 12.0 & 4.0 & 0.2 \\
\hline
\end{tabular}


formula as 8101330 . The arrangement of various drugs in the Table has been done based on this kind of comparison.

\section{Summary}

The following is the overall result obtained as a consequence of a comparison as regrads various sympathetic stimulants tested on the jejunums of domestic rabbits. Three sets of ratings as strong, medium and weak are used to indicate the quantity required to bring forth the prescribed function in the $40 \mathrm{~mol}$ Jyrode solution. The test drugs are given in the order of their effects.

\section{References}

1) TAmura, T. : Pharmacological functions of procaine, aspartic acid and glutamic acid compounds: Part. 1. Their Characters and Production Process, Medicine and Biology, Vol. 34, No. 5 (1954).

2) TAmURA, T. : Pharmacological functions of Procaine, aspartic acid and glutamic acid compounds: Part 2. On their anti-acetylcholine and Arthus phenomenon, Medicine and Biology, Vol. 35, No. 3 (1955).

3) Tamura, T.: Pharmacological functions of Procaine, aspartic acid and glutamic acid compounds: Part 3. On their anti-hyaluronidase and toxicity, Medicine and Biology, Vol. 35, No. 5 (1955).

4) TAmURA, T. and WADA, K. : Pharmacological functions of hydrazine hydrochloride and hexametonium compounds, Medicine and Biology, Vol. 35, No. 4 (1955).

5) Terada, B., TAmura, and Saito, A. : Pharmacological functions of Procaine, aspartic acid and glutamic acid compounds upon heart and respiratory movement, Shika-Geppo, Vol. 29, No. 1 (1955).

6) Nakazawa, Y. and TATENAKA, N. : Comparative study on pharmacological functions of Adrenalin, Noradrenalin and Adrenochrome derivatives, Journ. of Japan Pharma. Society Vol. 47, No. 2 (1951).

7) OzAKI, T. : Contents of Noradrenalin and Adrenochrome in adrenal glands of various animals, Journ. of Japan Physio. Society, Vol. 14, No. 4 (1952).

8) TANAKA, I. : On functions of Adrenalin, Noradrenaline and Isopropylnoradrenaline upon human sweat gland, Journ. of Japan Physio. Society, Vol. 17, No. 3 (1955).

9) TAnAKA, I. : Latest findings regarding Noradrenaline, Progress of Medicine Vol. 20, No. 5 (1955).

10) Stolz: Ber. d. deutsch. chem. Gesellsch, 37, 4149 (1904).

11) Goldenberg: American Journal of Medicine, 5792 (1948).

12) SAto, H. : Comparative study between Epinepherine and Norepinephrine as regards their cardiac blood vessel function, Journ. of Japan Physio. Society, Vol. 13, No. 11 (1951).

13) BARger and DALE: Journ. Physiol. 41, 19, (1942).

14) Keys and ViOlante: Journ. Clin. Invest., 21, 1 (1942).

15) Tanaka, T. : Latest vasoconstrictors in the field of surgery, Clinical Surgery, Vol. 9, No. 12 (1954).

16) Kitahara, S. : Clinical cases of Neocynezine, Surgery, 17, 1 (1955).

17) NAGASU, C. : By-effect of lumbal anesthesia and its prevention, Clinical Surgery, 10, 1 (1955).

18) Morishita, K. and Ogyu, K. : Pharmacology, 310, 376, 392 (1954).

19) Misawa, N. : Study on anti-allergic drugs, Tokyo Iji Shimpo, 68, 3 (1951).

20) KonZetT : Neue broncholytisch hoch-wirksame Körper d. Adrenalinreihe Arch. f. Exp. Path. u. Pharmacol. 197, 27 (1940).

21) KonZett : Zur Pharmacologie neuer Adrenalin verwander Körper, ibid. 197, 41 (1940). 
22) LANDS, et al. : J. Pharmacol. \& Exp. Therap. 90, 110 (1947).

23) SIEGM, et al. : Ibid, 90, 254 (1947).

24) Dertinger, et al. : J. Pharmacol. \& Exp. Therap, 90, 110 (1947).

25) Long, J. M., et al. : Journ. Am. Med. Assso. 139, 452 (1949). 